\title{
Understanding Heterogeneous Preferences of Cooperative Members
}

\author{
Nikos Kalogeras \\ Departments of Marketing \& Finance, Maastricht University, Tongersestraat 53, \\ 6211 LM, Maastricht, The Netherlands; Department of Agricultural and Consumer \\ Economics, University of Illinois at Urbana-Champaign, IL. \\ E-mail: n.kalogeras@finance.unimaas.nl
}

Joost M.E. Pennings

Departments of Marketing \& Finance, Maastricht University, Tongersestraat 53, 6211 LM, Maastricht, The Netherlands; Department of Agricultural and Consumer Economics, University of Illinois at Urbana-Champaign, IL; and Marketing \& Consumer Behavior Group, Wageningen University, The Netherlands.

E-mail: joost.pennings@finance.unimaas.nl

Ivo. A. van der Lans

Marketing \& Consumer Behavior Group, Wageningen University, Hollandseweg 1, 6706 KN Wageningen, The Netherlands. E-mail: Ivo.vanderLans@wur.nl

Philip Garcia

Department of Agricultural and Consumer Economics, University of Illinois at Urbana-Champaign, 326 Mumford Hall, MC-710, 1301 West Gregory Drive, Urbana, Illinois 61801. E-mail: p-garcia@uiuc.edu

Gert van Dijk

Marketing \& Consumer Behavior Group, Wageningen University, Hollandseweg 1, 6706 KN Wageningen, The Netherlands. E-mail: gertvandijk@wur.nI

\begin{abstract}
We study the heterogeneity in the preference structure of cooperative members. Using conjoint analysis the utility that members attach to intra-organizational and strategic attributes of their cooperative is elicited. Recognizing that members are not homogenous, a concomitant finitemixture regression model is employed to allow preferences to vary across different member segments. With data from 120 cooperative members, we find that most members demonstrate rather similar preferences for strategic attributes but differ with respect to the intraorganizational attributes of control and management. Members' preference structures are affected by business size and attitudes towards risk. [EconLit Citations: Q130; M000, C400]. (C) 2009 Wiley Periodicals, Inc.
\end{abstract}

\section{INTRODUCTION}

Identifying members' preferences and the heterogeneity for the attributes of cooperatives (co-ops) is fundamental for understanding co-ops' structure and behavior. Members involved in collective action often strive to influence corporate structure and decisions to reflect their preferences, resulting in organizational policies that fail to benefit the membership as a whole (Olson, 1965). Conflicting preferences can generate problems in a co-op setting. Increasing heterogeneity in members preferences may result in declining member commitment (Fulton \& Giannakas, 2001), decreasing 
member willingness to provide equity capital (Van Bekkum, 2001), increasing costs related to damaging influence activities (Cook, 1995), laborious decision-making processes (Hansmann, 1996), and incoherent strategic focus (Hendrikse \& Bijman, 2002). Despite their recognized importance within collective decision making and resulting organizational policies, knowledge of actual members' preferences for the attributes of co-op structure is limited. Most research has maintained a primarily analytical focus and studied the consequences of a priori heterogeneous preferences for single pricing and governance attributes (Cook, Chaddad, \& Iliopoulos, 2004). The lack of empirical evidence, which can negatively affect the quality of decision-maker choice and researcher understanding of co-op behavior, is due in part to data constraints as well as difficulties in determining member's preferences - which are not always directly observable - and in accounting for their heterogeneous nature.

Kalogeras, Pennings, Van Dijk, and Lans (2007) have conducted empirical research on members' preferences for attributes related to internal organization and strategic behavior of Dutch marketing co-ops to reveal what kind of co-op structure members mostly desire. They show that members on average prefer a more market-oriented management and an internal co-op structure closer to an investor-owned-firm (IOF), rather than the traditional proportional type. However, such average preferences may mask critical relationships when studying and analyzing agribusinesses' structures and producers' economic behavior (Pennings \& Leuthold, 2000). For instance, one might expect that not all members necessarily have the same preferences' structure because of differences in their own firm's characteristics. Here, we expand the literature by identifying the heterogeneity in member preferences (i.e., utility) for intra-organizational and strategic co-op attributes and assessing the factors that affect members' heterogeneous preferences for these attributes. We investigate attributes related to coop's equity, control, benefits' allocation, and planning and implementation of strategic positioning, and examine the effects of business size and risk attitude on preferences. We select these attributes because they are at the core of collective co-op structure and because of their importance for understanding the relationship between internal structure and co-op choice, particularly in a competitive marketing environment (e.g. Bijman, 2002; Hendrikse \& Veerman, 1997; Meulenberg, 1979, 2000). We investigate the effect of business size and risk attitude on preferences since these are common factors that emerge in the co-op literature (e.g. Banerjee, Mookherjee, Munshi, \& Ray, 2001; Buccola \& Subaei, 1985; Reynolds, 1997; Staatz, 1983; Zusman, 1992) to explain differences in preferences.

To address our objectives, we use a research design that includes focus groups, individual member interviews, conjoint analysis and a concomitant finite mixture regression model. In the empirical analysis, we investigate the preferences of agricultural co-op members of a Dutch marketing co-op, VTN/The Greenery (VTN/ TG). Co-ops are dominant in the Dutch economy, particularly in banking, financial services, and agribusiness. In the last decade, similar to many U.S. co-ops, Dutch horticultural co-ops have restructured their economic activities, evolving toward entrepreneurial organizations that increasingly adopt IOF-like organizational attributes. Investigation of the VTN/TG, which is experiencing this change, permits an opportunity to develop an understanding of producer concerns and their implications for co-op structure during this transition. Our use of a case-study method is consistent with Sterns, Schweikhardt, and Peterson's (1998) call for more detailed investigations of business firms in agriculture, and Cotterill's (2001) 
recommendations for agricultural co-op research to develop a better understanding of economic behavior. The elicitation framework combined with the concomitant mixture approach permits us to identify segments in which members posses a similar preference structure and relate these segments to member characteristics (Wedel \& Kamakura, 1998). The analysis provides an opportunity to gain insight at a highly disaggregate level into member preferences for their co-op structure and the degree of heterogeneity that exists even in one marketing co-op. Further, the investigation allows for a more comprehensive understanding of the behavior of co-op members, and it permits an assessment of the factors affecting behavior that are often the maintained hypotheses in more aggregate analysis.

The remainder of the article is structured as follows. The Heterogeneity in Member Preference Structures section discusses the organizational attributes of coops and the factors influencing heterogeneity in member preference structures. The Empirical Model section explains the statistical specifications of our empirical model. The Empirical Design and Results and Discussions sections describe the research design and present the empirical findings. Finally, conclusions and implications follow.

\section{HETEROGENEITY IN MEMBER PREFERENCE STRUCTURES}

This study focuses on the diversity in members' preferences for co-op attributes. Emphasis is placed on the individual and subgroups preferences for these key organizational attributes of a co-op. First, we discuss these attributes and then the factors affecting heterogeneity in member preferences.

\subsection{Attributes of Cooperatives}

Building on principles of co-op organization and drawing from recent literature that emphasizes market challenges that co-ops face, we focus on two set of attributes: intra-organizational and strategic attributes.

Intra-organizational attributes are based on the definition of co-op as user-owned and user-controlled business that distributes benefits on the basis of use (USDA, 1995). The definition encompasses the basic foundation on which a co-op's internal structure is built: collective equity, control, and benefit allocation to user-owners. Agricultural co-ops have traditionally adhered to exclusive members' ownership in the form of direct investments or retained patronage refunds (Knoeber \& Baumer, 1983), democratic control (Barton, 1989), and uniform pricing policy (net income allocation through product prices). However, many co-ops, in order to adapt to agricultural industrialization, have relaxed one or more of these traditional principles, allowing for individualized equity shares, inviting nonmember parties to partially finance their operations, applying proportionality in decision control, and allocating net benefits through price and personal shares. The extent to which co-ops relax their definitional principles influences their organizational form, ranging from traditional to more individualized (Van Bekkum, 2001) or IOF-like entities (Chaddad \& Cook, 2004). ${ }^{1}$

\footnotetext{
${ }^{1}$ For a detailed description of the organizational attributes of various co-op models and the problems encountered with the different collective structures, see Cook and Iliopoulos (2000) and Chaddad and Cook (2004).
} 
Strategic attributes refer to strategic market choices made by co-ops. Co-ops' emulation of IOF-like organizational structures permits the acquisition of risk capital for the implementation of growth-related strategies to increase competitiveness (Bergman, 1997; Oustapassidis, Vlachvei, \& Karantininis, 1998). Specific strategic choices determine the core characteristics of co-ops' marketing mix and positioning (Meulenberg, 1979; Van Dijk \& Mackel, 1991). For example, co-ops must choose among cost-leadership, product differentiation, and focus-segmentation strategies that can increase their competitive advantage (Meulenberg, 2000). Strategic management theory suggests a firm's competitive advantage is derived from its ability to produce value by acquiring leadership in market knowledge and bringing its resources to their optimum value in a sustainable manner (e.g., Porter, 1985; Bucklin \& Sengupta, 1993). The co-op's choice among different market strategies is especially critical in dynamic agricultural markets (Peterson \& Anderson, 1996) or in periods of structural change where products become outdated and adaptation is required (Goldsmith \& Gow, 2005).

\subsection{What Influences Members' Heterogeneity?}

Co-op members have direct access to the decision-making process and can influence its financing, benefits allocation, corporate governance, and strategic choices (Staatz, 1987; Hansmann, 1996). Members can possess disparate preferences for attribute alternatives and disagreements can emerge as to which combination is most desirable (Zusman, 1992). Conflicting preferences that are most likely to emerge in periods of transition (Holmstrom, 1999) can cause inefficient resource allocation (Staatz, 1983) and force co-ops to adapt. As analyzed by Hansmann (1996) and discussed by Vitaliano (1983) and Cook (1995), the divergence in incentives and preferences is particularly problematic for the assignment of contractual property rights among members with diverse characteristics. That is, members with different characteristics and conflicting preferences are inclined to compete for rents.

Research has demonstrated that a decision-maker's environment can influence decision criteria and preferences (March \& Shapira, 1987; Pennings \& Leuthold, 2000; Pennings \& Garcia, 2004; Smidts, 1990). In a related vein, co-op researchers have maintained that the variance in the business size of members (e.g. Banerjee et al., 2001; Gripsurd, Lenvik, \& Olsen, 2001; Iliopoulos \& Cook, 1999; Reynolds, 1997; Staatz, 1987) and risk attitude (e.g. Buccola \& Subaei, 1985; Vitaliano, 1983; Zusman, 1992) are relevant factors influencing differences in members' preferences for a co-op's governance structure. In this context, the "large versus small" effect is the most important paradigm for explaining heterogeneity. Differences in members' cost efficiency associated with business size (large low-cost compared to small highcost producers) have been hypothesized to affect their efforts to capture the rents generated by the risk-bearing capital activities of co-ops.

A co-op's ability to help members to successfully manage the riskiness of their assets is often subject to an equity acquisition problem, known in co-op literature as "portfolio problem" (Cook, 1995). The cause of this problem, which often occurs within traditional co-ops, is the absence of secondary markets for trading, liquidating, and investing residual claims (lliopoulos, 1998). The absence of relevant secondary markets may prevent members from adjusting co-op asset portfolio to 
their own risk preferences (Vitaliano, 1983). In this situation, members with differing risk preferences may argue for differentiated governance policies that better represent their risk portfolio (Cook \& Iliopoulos, 2000).

In the article, we follow an approach that emphasizes the role of theory in the empirical analysis as attributes are used to discriminate among segments of members with similar preferences as well as to identify how business size and risk attitude affect the diversity in member preferences. The procedure allows for segmentation of co-op members based on their underlying latent decision-making process, and it is consistent with Heckman's (2001) thinking that the underlying decision-making process of individual market participants (e.g. producers, investors, consumers) drives heterogeneity in behavior.

\section{EMPIRICAL MODEL}

The subjective utility that members attach to particular attributes is identified using an additive conjoint model. Conjoint analysis assumes that decision makers derive utility from the attributes of a product or service (Green \& Rao, 1971). Levels (alternatives) of the selected co-op attributes contribute to members' overall utility as given in Equation 1,

$$
y_{j k}=\sum_{p=1}^{P} \sum_{l=1}^{L_{p}} x_{j k l p} \beta_{j l p}+e_{j k}
$$

where $y_{j k}$ is the preference of respondent $j(j=1, \ldots, J)$ for profile $k(k=1, \ldots, K)$, which represents a hypothetical marketing co-op design; $p(p=1, \ldots, P)$ is an index for attributes, with $P$ being the total number of attributes; $l\left(l=1, \ldots, L_{p}\right)$ is an index for attribute levels, with $L_{p}$ being the number of levels defined for attribute $p$; $x_{j k l p}$ is a dummy variable that takes a value of 1 when level $l$ of attribute $p$ holds in profile $k$ for $j$ and $x_{j k l p}=0$ otherwise; and $\beta_{j l p}$ is the utility that member $j$ attaches to level $l$ of attribute $p$, and $e_{j k}$ is a normal i.i.d. error term with variance $\sigma^{2}$.

Based on the structure of preferences $\left(y_{j k}\right)$, which is often defined in terms of a specific scale or metric and the value of the dummy variables $\left(x_{j k l p}\right)$, the utility weights $\left(\beta_{j l p}\right)$ can be estimated for each member. Often, assuming that the attributelevel utilities are the same for all members, preferences are combined. Here, we allow for heterogeneity of attribute-level utilities across members.

To account for heterogeneity, we apply a finite-mixture regression model to the conjoint data (DeSarbo, Wedel, Vriens, \& Ramaskamy, 1992). In finite-mixture regression models, the sample of observations arises from a specified number of underlying populations (i.e. segments) of unknown proportions. A specific form of the density of observations in each of the underlying populations is specified. In our case, we specify these densities in terms of a common (across segments) regression equation (Equation 1) with segment-specific regression weights and error-term variances. The approach permits simultaneous identification of segments and their respective sizes and the estimation of attribute-level utilities for each identified segment. In addition, posterior probabilities of segment membership are obtained for each co-op member in the sample.

Members are assumed to come from a population that is composed of $S$ unobserved segments, with relative mixing proportions $\pi_{1}, \ldots, \pi_{s}$ that are subject to 
the following constraint:

$$
\sum_{s=1}^{S} \pi_{s}=1, \quad \pi_{s} \geq 0, \quad \text { and } \quad s=1, \ldots, S
$$

The mixing proportion $\pi_{s}$ is the prior probability that a member belongs to segment $s$.

The distribution of $y_{j k}$, given that the member $j$ comes from segment $s$, is from the exponential family of distributions and denoted as $f_{j k \mid s}\left(y_{j k}\right)$. The exponential family includes the normal, binomial, Poisson, and gamma distributions. We assume a normal distribution since it has been shown to work well for rating-scaled conjoint data (DeSarbo et al., 1992), and the multivariate statistical nature of additive conjoint framework allows the joint effects of the independent variables to be normally distributed (Harris, 1975). Given segment $s$ the expectation of $y_{j k}$ is denoted by a linear predictor $\partial_{s j k}$ with i.i.d. error term and variance $\sigma_{s}^{2}$. Within segments, these expectations are a function of the set of explanatory variables $\left(\sum_{p=1}^{P} \sum_{l=1}^{L_{p}} x_{j k l p}\right)$ - the representation of the attributes - and the segment-specific utility weights $\beta_{l p s}$ in segments $s$

$$
g\left(\partial_{s j k}\right)=\sum_{p=1}^{P} \sum_{l=1}^{L_{p}} x_{j k l p} \beta_{l p s}
$$

where $g($.$) is a link function. The function links the expectations of member preference$ measurements to the co-op attributes in segment $s$. The $\beta_{l p s}$ and the $\sigma_{s}^{2}$ differ across segments.

The unconditional probability density function of an observation $y_{j k}$ is now expressed in the finite mixture form

$$
f_{j}\left(y_{j k} \mid \Phi\right)=\sum_{s=1}^{S} \pi_{s} \prod_{k=1}^{K} f_{j k \mid s}\left(y_{j k} \mid \beta_{s}\right)
$$

where $\Phi$ is the vector including all parameters $\left(\pi_{s}, \beta_{l p s}\right.$, and $\left.\sigma_{s}\right)$ and the likelihood for $\Phi$ is

$$
L(\Phi ; y)=\prod_{j=1}^{J} f_{j}\left(y_{j} \mid \Phi\right)
$$

where $y_{j}$ is the observation vector $y$ of member $j$.

As discussed, we expect that the business size and risk attitude of members will affect differences in member preferences. These factors are incorporated in the finitemixture models as so-called concomitant variables (cf. Wedel \& Kamakura, 1998). That is, we now specify the conditional distribution of the member's preference structure for marketing co-op's design, given the two concomitant variables. The core of this submodeling is that the prior probabilities of each potentially identified segment can be reparameterized by a multinomial logit model in terms of function of the concomitant variables as shown in Equation 6.

$$
\pi_{s / Z}=\frac{\exp \left(\sum_{\lambda=1}^{\Lambda} \gamma_{\lambda s} z_{j \lambda}\right)}{\left.\sum_{S=1}^{S} \exp \sum_{\lambda=1}^{\Lambda} \gamma_{\lambda s} z_{j \lambda}\right)}
$$

where $\lambda=1, \ldots, \Lambda$ is an index for concomitant variables, $\gamma_{\lambda s}$ denotes the impact of the $\lambda^{\text {th }}$ concomitant variable on the prior probability of segment $s, z_{j \lambda}$ the value of $\lambda^{\text {th }}$ 
concomitant variable for member $j$, and $z_{j}$ is a vector of values of respondent $j$ on the $\Lambda$ concomitant variables. For identification purposes it is commonly assumed that $\gamma_{\lambda S}=0$. The parameters of the multinomial logit submodel are specific to each concomitant variable and member segment. A positive $\lambda_{\lambda S}$ implies that a higher value of a concomitant variable increases the probability that a member $j$ belongs to segment $s$.

The unconditional probability of $y_{j}$ is now obtained by combining the unconditional probabilities of Equation 4 with the reparameterized probabilities from Equation 6 . So, $\pi_{s}$ is replaced by $\pi_{s / z}$ which varies systematically across members

$$
f_{j}\left(y_{j k} \mid \Phi\right)=\sum_{s=1}^{S} \pi_{s / Z} \prod_{k=1}^{K} f_{j k \mid s}\left(y_{j k} \mid \beta_{s}\right)
$$

Equation 7 accounts for influence of the concomitant variables on the conjoint equation's probability density function. The parameter vector $\Phi$ (also including the $\gamma_{\lambda s}$ ) in Equation 7 is estimated via maximum likelihood using the expectationmaximization (EM) algorithm. The likelihood describes the probability that the data are generated given the specific set of model parameters, and its maximization gives the set of parameters most likely to have given rise to the data. The EM algorithm is used because dummy indicators (i.e. the $0 / 1$ membership of the producers in the segments) are introduced that specify to which particular segment each member belongs but are considered to be missing. The EM algorithm involves calculating posterior membership probabilities according to Bayes' rule and the current parameter estimates of $\Phi$ and substituting them into the likelihood as estimates of the unknown dummy indicators, in an $\mathrm{E}$ (expectation)-step. Once this is accomplished, the likelihood is maximized over the parameter space $\Phi$, in an $M$ (maximization) step. Given new estimates of $\Phi$, new posteriors are calculated in the next E-step, followed by a new M-step to find a new $\Phi$. The E- and M-steps are repeated until convergence. ${ }^{2}$

The actual number of member segments is unknown and, in practice, must be inferred. We use Bozdogan's (1987) consistent Akaike's information criterion (CAIC) to determine the number of segments. ${ }^{3}$ The CAIC is defined as

$$
\mathrm{CAIC}=-2 \ln L+(P \cdot S+S-1)(\ln (J)+1) .
$$

The CAIC gives a trade-off between the likelihood and the number of estimated parameters. The number of segments for which CAIC reaches a minimum is supposed to give the best trade-off. In addition, for any set of identified segments an Entropy statistic, $E_{s}$, is calculated to assess whether the

\footnotetext{
${ }^{2} \mathrm{~A}$ general description of the procedure is given by Wedel and Kamakura (1998).

${ }^{3}$ Formal tests for the number of segments, such as the likelihood ratio test, can not be applied to this class of mixture models because the asymptotic properties of these tests do not hold (Aitkin \& Rubin, 1985; Titterington, 1990). We follow the mixture literature by using the CAIC, which also is burdened by the same difficulty, as a heuristic guide for determining the number of segments. Evidence from Monte Carlo and other studies find that the framework works well except when many parameters are estimated and the segments are not well separated (Pennings \& Garcia, 2004; Wedel \& DeSarbo, 1995). Deterioration in performance has been ascribed to convergence to local optima. In light of these findings, we use different starting values and determine whether the segments are well separated to support our analysis.
} 
segments are well separated. $E_{s}$ is defined by

$$
E_{s}=1-\sum_{j=1}^{J} \sum_{s=1}^{S}-\alpha_{j s} \ln \alpha_{j s} / J
$$

where $\alpha_{s j}$ is the posterior probability that member $j$ comes from latent segments $s$. The posterior probability is also affected by the concomitant variables and is used to classify members in a specific segment. It can be calculated for each observation vector $y_{j}$ given an estimate of $\Phi$ using Bayes' Theorem

$$
\alpha_{s j}\left(y_{j}, \Phi\right)=\frac{\pi_{s / Z} \prod_{k=1}^{K} f_{j k \mid s}\left(y_{j k} \mid \beta_{s}\right)}{\sum_{s=1}^{S} \pi_{s / Z} \prod_{k=1}^{K} f_{j k \mid s}\left(y_{j k} \mid \beta_{s}\right)} .
$$

$E_{s}$ in Equation 9 is a relative measure bounded between 0 and 1 and describes the degree of separation in the estimated posterior probabilities. $E_{S}$ values close to 1 indicate that the posterior probabilities of the respondents are close to 1 and 0 and therefore the segments are well defined. $E_{s}$ values close to 0 indicate that segments are not well defined.

\section{RESEARCH DESIGN}

Case studies can be useful in developing an in-depth understanding of economic behavior of agribusinesses (Sterns et al., 1998) and agricultural co-ops (Cotterill, 2001). They permit a detailed assessment of the factors affecting behavior, which are often the maintained hypotheses of more aggregate analysis. The focus of the casestudy on member preferences for combinations of co-op attributes and the factors that influence their heterogeneity may generate a more comprehensive understanding of the behavior of co-op members and can assist in supporting more aggregate analyses.

To study preferences, complementary qualitative and quantitative methods are used. Qualitative data on relevant co-op attributes are collected from archived data sources and focus-group discussions with co-op members, which later inform the design of the conjoint study. Rohner (1977) argues that such a research design provides an accurate description and evaluation of preferences because data on a topic are collected using independent methods that do not share similar potential bias.

\subsection{Decision Context}

For empirical analysis, a decision context is required where members have a prominent influence on the internal organization of a co-op as well as the development of its marketing strategy. Marketing co-ops operating in the horticultural sector meet this requirement because members who produce highly perishable products are in the position to determine the product attributes and, for the most part, are able to provide essential post-harvest handling. We investigate the preferences of co-op members of a Dutch fruit and vegetable co-op, VTN/TG. Co-ops are dominant in the Dutch economy, particularly in the agribusiness sector. In the last decade, Dutch horticultural co-ops have evolved toward entrepreneurial organizations that increasingly adopt IOF-like structural attributes (Van Bekkum \& Van Dijk, 1997). VTN/TG is experiencing such a transition. 
The Greenery (TG) sells, distributes, and markets fresh produce. It was established in 1996 and its shares are owned by the horticultural co-op Voedings Tuinbouw Nederland (VTN), which emerged from a merger of nine vegetable co-op auctions because members were dissatisfied with the marketing performance of the auction system. The 2,500 producer-owned members of VTN market/sell their products through TG (VTN/TG Annual Report, 2003). The co-op VTN is the only shareholder of TG whose business goal is to realize for their members the best product price/income by an effective and efficient marketing and selling policy. VTN/TG sells a wide variety of fresh horticultural commodities, including paprika, cucumbers, tomatoes, green-salads, apples, and strawberries. The participating member firms are mostly family owned and the manager is often the owner. Based on sales value, VTN/TG is the largest fruit and vegetable company in the Netherlands (Bijman \& Hendrikse, 2003). Recently, due to a reduction in members' commitment to TG's operations and growing members' heterogeneity, VTN/TG has passed through several restructuring phases.

The transformation of co-op auctions, which maintained traditional co-op attributes, into a market-driven business entity resulted in a collective venture that combined both collective and IOF-like organizational attributes. VTN/TG offered a mix of collective and individual ownership titles to members to raise adequate equity capital to support the implementation of its marketing strategy. Its residual decision rights were exercised by members, professional management, and supervisory boards in which both members (represented by VTN's Board of Directors [BOD]) and market experts participate. Members and managers also participate in productmarket decisions. Adaptation to this organizational form was influenced by diversity in economic interests of participating member-investors.

Differences in members' interests led to the establishment of Product Market Advisory Committees (PMACs). From the start, members have exercised control rights in VTN and represented themselves in transactions with the TG through PMACs. Also, the EU's subsidizes to establish additional marketing associations in the European agribusiness sector stimulated VTN producers to form various product-specific bargaining associations. Hence, VTN producers further splintered into subgroups with different crop-specific interests and concerns. The formation of these associations was mainly influenced by members' dissatisfaction with the lack of transparency between VTN/TG's supervisory board and TG's management board, inadequate management of product-related grading, pricing and selling, and a benefit system that disproportionately cross-subsidized specific groups (Bijman, 2002). Members were concerned by a loss of control over TG's marketing policies, which they felt were implemented without sufficient producer input (Kyriakopoulos, 2000). In response, VTN/TG has attempted on several occasions to implement policies to reinforce its members' commitment and to attract members' investments for its marketing operations.

\subsection{Relevant Attributes: Focus-Group Findings}

In winter 2002, TG's sites were visited to develop an understanding of member preferences for attributes of VTN/TG. Differences in economic interests among members and conflicting views on the organizational structure and strategic behavior of VTN/TG were apparent. The substantive change from a co-op auction system to a 
marketing organization that entails both traditional co-op' and IOF's-like organizational attributes was the issue of concern. To identify more precisely the relevant attributes, two focus groups sessions were conducted. Fifteen members, who were selected to provide a wide range of characteristics including age, region, differences in products, enterprise age and structure, and involvement in the co-op, participated in each session. Members were asked to discuss VTN/TG's intraorganizational and strategic attributes.

Discussions identified six attributes, each with two levels (i.e. alternatives), as important attributes of VTN/TG (Table 1). Four intra-organizational attributes (member benefits, corporate governance, product-related decision making, and financial structure) and two strategic attributes (business scope and product quality/ grading) emerged, which we summarize below with the alternatives or questions that reflect the diversity in members' preferences.

4.2.1. Members' benefits. Members' opinions on how net income should be allocated were split. Some participants supported the traditional notion that performance should be based primarily on net price through a well-defined contract between the co-op and the member (i.e. based on a proportional pricing mechanism). Other members preferred a mechanism based on return on capital invested in addition to the product price.

4.2.2. Corporate governance. The need to ensure corporate control of VTN/TG's activities by effective collaboration among members, the board of directors (BODmembers' representatives) and hired managers was important to all participants.

TABLE 1. Intra-Organizational and Strategic Attributes: VTN/The Greenery ${ }^{\mathrm{a}}$

\begin{tabular}{|c|c|}
\hline Attributes & Attribute levels (alternatives) ${ }^{\mathrm{b}}$ \\
\hline \multicolumn{2}{|l|}{ Intra-organizational } \\
\hline \multirow[t]{3}{*}{ Members' benefits } & 1. Product price \\
\hline & 1. Product price \\
\hline & 2. Product price and return on capital \\
\hline \multirow[t]{3}{*}{ Corporate governance } & 1. $V T N:$ Board of Directors (BOD) \\
\hline & $T G$ : Managers supervised by VTN's BOD \\
\hline & $\begin{array}{l}\text { 2. VTN: Managers supervised by VTN's BOD } \\
T G \text { : Managers supervised by } \text { PSB }^{\mathrm{c}}\end{array}$ \\
\hline \multirow[t]{2}{*}{ Product-related decision making } & 1. Members \\
\hline & 2. Managers \\
\hline \multirow[t]{2}{*}{ Financial structure } & 1. General reserves \\
\hline & 2. Individualized equity \\
\hline \multicolumn{2}{|l|}{ Strategic } \\
\hline \multirow[t]{2}{*}{ Business issue/scope } & 1. Market-oriented organization \\
\hline & 2. Intermediary organization \\
\hline \multirow[t]{2}{*}{ Product quality } & 1. General grading of products \\
\hline & 2. Client-specific grading of products \\
\hline
\end{tabular}

Note: ${ }^{a} V T N$ is the horticultural co-op, Voedings Tuinbouw Nederland. TG is the Greenery (marketing firm) that markets fresh produce for the co-op $V T N$, who is its only shareholder. ${ }^{\text {b}}$ Each attribute has two levels (alternatives). ${ }^{\mathrm{c}} \mathrm{PSB}=$ professional supervisory board. 
However the preferred structure of control (governance) varied. One form placed corporate control primarily in the hands of the BOD, which would directly administer VTN (co-op) and supervise hired managers who would assume the role of board of directors of TG (marketing firm). The alternative form was for hired managers to administer VTN under the supervision of the BOD and for managers to also administer TG (as in previous form) but under the supervision of a professional board. This professional supervisory board of directors (PSB) would include external nonmember professionals (i.e. experts) and the member representatives would be a minority. The general assembly of members would appoint and supervise the PSB.

4.2.3. Product-related decision making. The relevant question here is: Who should determine VTN/TG's product quality, price setting, and sales methods for different market segments? Members indicated their dissatisfaction with current pricing procedures and marketing strategies. Some members wanted to make decisions directly on these product-related issues themselves (through VTN BOD's, PMACs', and established crop-specific associations' representation), while others indicated that they were more comfortable placing the decisions in the hands of knowledgeable market managers.

4.2.4. Financial structure. Members explained that capitalization was a contentious and major problem for implementing VTN/TG's marketing plan. The introduction of individual ownership titles gave the residual right to members for cumulative preferential dividends and resulted in low equity/debt ratios for TG through 2002. Some members indicated that establishment of a traditional general reserves system might be the solution for increasing equity capital through retained earnings. In contrast, others preferred increasing VTN/TG's equity by issuing individual ownership titles.

4.2.5. Business scope/concept. Members were concerned that the scope of VTN/TG's business operations did not capture their economic interests. Members indicated that VTN/TG needs to maintain its user orientation as it increases in economic size and managerial complexity. However, there were differences regarding whether VTN/TG should solely act as an intermediary channel that buys and sells its members' produce or be active in developing a more comprehensive market-oriented firm in its own right.

4.2.6. Product quality. Finally the critical role of product quality in VTN/TG's marketing strategy received considerable attention. Two main strategies emerged. Several members felt that the co-op should follow a more traditional path of selling rather generic products using the market's general grading schemes. This strategy would be based on competitive prices, efficiency in production and logistics, and serve price-conscious consumers. In contrast, other members felt strongly that VTN/ TG should focus on marketing products to meet client-specific quality needs.

\subsection{Design of Conjoint Study}

The findings from the group sessions were used to design the conjoint study. The method allows members to evaluate the tradeoffs of VTN/TG's attributes (Hauser \& 
Rao, 2005). The number of identified attributes permits a full-profile conjoint design (Green \& Srinivasan, 1990). A 2 (Business Issue/Scope) $\times 2$ (Corporate Governance $) \times 2$ (Product-Related Decision-Making $) \times 2$ (Financial Structure $) \times 2$ (Members' Benefits) $\times 2$ (Product Quality) fractional factorial main-effect-only design generated a set of eight calibration profiles. Profiles refer to hypothetical marketing co-op designs described by combinations of attributes' alternatives identified in Table 1. A main-effects design was selected to keep the number of profiles manageable for respondents.

Members who participated in the conjoint interviews were selected using a stratified sample design. Producer degree of involvement in VTN/TG's decision making (holding positions/participating in decision- or co-decision-making bodies, e.g. PMACs), economic size (sales value $>75,000$ Euros), and primary income from on-farm activities were the sample selection criteria. Involvement in decision making was seen as important to determine awareness of the situation faced by the co-op. The sales value was selected to reflect a level of active market participation, while still permitting for a representative range of producers. VTN/TG's public relations office provided us with a list of 500 members satisfying the criteria. Each member was contacted twice (via mail and telephone). Initially, 172 members expressed interest in participation. Later, some members declined to participate when informed that the conjoint task required a 45-minute interview. Other practical reasons (i.e. time and cost constraints) led us to conduct the large-scale conjoint interview with 120 members. ${ }^{4}$ The average age of participating members was 41.6 and the majority $(70.1 \%$ ) had a college degree (a skilled farm management degree). Also, the vast majority of members reported no off-farm business activities $(81.7 \%)$, and a sharing of firm equity among family members $(79.2 \%)$.

All interviews were computer-guided and performed on an individual basis. Care was taken to build a user-friendly interface. A pilot test based on eight producers was conducted to check the degree in which members understood the conjoint task. Prior to evaluation of the hypothetical marketing co-op profiles, members were permitted to study definitions of the attributes and their levels and to ask clarifying questions. No serious problems were encountered in the interviews.

To reflect preferences, members were asked to rate the eight profiles using a 9-point rating scale that ranged from 1 (least preferred) to 9 (most preferred). Members were also asked to indicate the degree of their agreement with statements referring to their own risk behavior using a 7-point scale (see Appendix).

\section{RESULTS AND DISCUSSION}

Prior to estimating the conjoint mixture model the preference ratings for each member were centered. This procedure helps avoid biases that can emerge when respondents use different reference points to evaluate the profiles (Dillon, Frederick, \& Tangpanichdee, 1985) and can reduce the effects of possible errors that may arise in the measurement of directly unobservable preferences. The conjoint model (Equation 1) using the mixture regression framework was applied to the data

\footnotetext{
${ }^{4}$ The managing director of VTN/TG affairs and secretary to the VTN's BOD indicated that the 120 members who participated in the conjoint study maintained average sales values similar to the producers identified in our stratified sampling design.
} 
allowing for up to 6 segments, $S=1$ to 6 . The log-likelihoods, CAIC statistics, $R^{2}$ and entropy value $\left(E_{S}\right)$ are reported in Table 2.

Based on the minimum of CAIC statistic, we select $S=2$ as the appropriate number of segments. The solution has a log likelihood of -1846.859 and an $R^{2}$ of 0.198 . The entropy value $\left(E_{s}\right)$ of 0.759 indicates that the segments are well separated; the posteriors are close to 1 or to 0 . In Table 3 the regression coefficients for each attribute, the coefficients of the members' business size and risk attitudes (concomitant variables), and the relative size of each identified segment are presented. For the attributes, the sign of the coefficient indicates which attribute level (see Table 1 for the alternatives) is preferred. A positive sign (the utility weigh is increasing) indicates that level 2 is preferred to level 1, while a negative sign (the utility weight is decreasing) indicates the opposite. For example, a positive sign for the member benefits attribute indicates that the benefit plan that combines product price and return on capital is preferred over the plan based on product price only. ${ }^{5}$ For the concomitant variables, positive coefficients indicate higher values of business size or an increased willingness to accept risk increase the probability that a member belongs to segment $s .^{6}$

Using our procedure, statistical tests can be performed to determine whether an attribute effectively explains the preference structure (i.e. drives the utility of individual members) in a particular segment. In both segments, members demonstrated rather well-defined preferences for attributes as gauged by their statistical significance $(p<0.05)$, substantiating the overall structure of the research design and supporting the notion that attributes contribute additively to member's utility. The results demonstrate the existence of two member-segments with dissimilar preferences for several attributes. In the two segments, three intraorganizational attributes have different signs while the signs for member benefits' and strategic attributes are the same. Members in segment 1 want VTN/TG to act as a market-oriented organization administered mainly by professionals for corporate and product-related issues that implement a marketing strategy based on clientspecific product quality. In particular, these members prefer corporate management delegated to hired managers under the supervision of the VTN's BOD. Hired managers are also preferred to administer TG under the supervision of PSB (professional supervisory board) consisting mainly of external non-member professionals. Also, they prefer to receive benefits through a mechanism that combines product price and return on capital. Members in segment 2 have similar preferences for the strategic attributes and member benefits' mechanism. However, they favor a governance structure where the BOD holds almost full decision control at the corporate level and where the members exercise product-related decision making through the BOD or PMACs. They also favor opportunity for individualized equity, which was not significant for segment 1.

\footnotetext{
${ }^{5}$ In Table 3, we identify the preferred level that corresponds to Table 1 below the estimated attribute coefficients in brackets.

${ }^{6}$ Business size is a ranking from 1 through 6 to reflect producer annual sales classifications (see Table 4) used in the interview. The risk-attitude measure described in the text was validated using confirmatory factor analysis (Pennings \& Smidts, 2000). The reliability measure, which ranges between 0 and 1 with higher values indicating superior reliability (See Hair, Anderson, Tathem, \& Black, 1998), is 0.78.
} 
TABLE 2. Fit Statistics of the Mixture Models for the Segments, $S=1$ to $S=6$

\begin{tabular}{llccc}
\hline Segment $S$ & Log likelihood & CAIC $^{\mathrm{a}}$ & $E_{\mathrm{s}}$ & $R^{2}$ \\
\hline 1 & -1921.240 & 3905.417 & 1.000 & 0.023 \\
2 & -1846.859 & 3827.456 & 0.756 & 0.198 \\
3 & -1828.403 & 3861.347 & 0.749 & 0.285 \\
4 & -1807.532 & 3890.307 & 0.790 & 0.327 \\
5 & -1798.519 & 3943.184 & 0.764 & 0.362 \\
6 & -1786.457 & 3989.861 & 0.791 & 0.424 \\
\hline
\end{tabular}

${ }^{a}$ CAIC is the consistent Akaike's information criterion and is used to determine the optimal number of segments. $E_{s}$ is the entropy statistic that is bounded between 0 and 1 and describes the degree of separation in the estimated posterior probabilities. $E_{s}$ values close to 1 indicate that the posterior probabilities of the managers belonging to specific segment are close to either 0 or 1 ; the segments are well defined.

TABLE 3. Mixture Regression Results for the Two-Segment Solution

\begin{tabular}{lcc}
\hline & \multicolumn{2}{c}{ Regression coefficients $^{\mathrm{a}}$} \\
\cline { 2 - 3 } Explanatory variables & Segment 1 & Segment 2 \\
\hline Intra-organizational attributes & $0.354^{*}$ & $0.444^{*}$ \\
Members' benefits & {$[2]$} & {$[2]$} \\
Corporate governance & $0.186^{*}$ & $-0.604^{*}$ \\
& {$[2]$} & {$[1]$} \\
Product-related decision making & $0.169^{*}$ & $-0.778^{*}$ \\
& {$[2]$} & {$[1]$} \\
Financial structure & -0.092 & $0.653^{*}$ \\
& {$[1]$} & {$[2]$} \\
Strategic attributes & & \\
Business issue/scope & $-0.308^{*}$ & $-0.738^{*}$ \\
& {$[1]$} & {$[1]$} \\
Product quality & $0.291^{*}$ & $0.636^{*}$ \\
Concomitant variables & {$[2]$} & {$[2]$} \\
Business size & & \\
Risk attitude & $0.995^{*}$ & $-0.445^{*}$ \\
Relative segment size & $0.279^{*}$ & -0.126 \\
\hline
\end{tabular}

${ }^{\mathrm{a}}$ A positive sign for the coefficient of an attribute indicates that alternative 2 is preferred to level 1 (Table 1 ) and a negative sign the opposite. For instance, the positive sign for coefficient of members' benefits indicates that the "product price and return on capital" is preferred to "product price." The preferred attribute level also is displayed below the value of the regression coefficients using [1] and [2] for the levels. ${ }^{\mathrm{b}} \mathrm{A}$ positive sign for the coefficient of the concomitant variables indicates that increases in the factor increase the probability of being in a segment, a negative sign the opposite.

*denotes significant at $p<0.05$.

The importance of the concomitant variables provides insight into the factors affecting the differences in preferences between the two segments. Increases in business size and risk attitudes significantly affect, but in opposite directions, the probability of being in the segments. Increases in business size increase the 
probability of being in segment 1 than in segment 2 . Increases in risk attitude increase the probability of being in segment 1 , but negatively affect (although not statistically significant) the probability of being in segment 2. Further, the estimated values of the regression coefficients of the concomitant variables are larger in segment 1 , implying that these factors have a stronger effect on membership in this segment.

To gain further insight, characteristics of the identified segments are presented (Table 4). A clear picture begins to emerge. While the proportions of the members in fruit and vegetable production are similar, the segments differ based on business size. Segment $1(n=37)$ is characterized by larger-sized enterprises with almost $50 \%$ percent reporting annual sales of more than 1 million euros and employing an average of 26 workers. In contrast, segment $2(n=83)$ contains smaller enterprises with an average of 5 workers and almost $75 \%$ reporting annual sales of less than 750,000 euros. These profiles support the significant effect of business size as a discriminating factor of the preference structure in both segments.

The revealed preferences demonstrate that members agree that VTN/TG should act as a market-oriented organization from which its members as users and investors capture benefits from marketing and selling policies that target end-user demand. These findings support and extend the conclusions identified by van Dijk and Mackel (1991), Meulenberg (1979, 2000), Bergman (1997), and Kyriakopoulos (2000) that co-ops offer higher benefits to participating members when focused on long-run planning and invest in aggressive marketing strategies to increase their growth and market power. In contrast, the results show a lack of consensus between the two segments on issues related to the intra-organizational control. Larger-sized members in segment 1 appear to believe that market leadership can be captured only by experts and that such a corporate governance plan is better suited to TG in its pursuing of market-oriented strategies. Smaller-sized members in segment 2 disagree with this governance scheme, opting for more member-oriented

TABLE 4. Descriptive Statistics of the Two-Segment Solution

\begin{tabular}{lcc}
\hline & Segment 1 & Segment 2 \\
\cline { 2 - 3 } & $(n=37)$ & $(n=83)$ \\
\hline Percentage of member type in segments: & & \\
Fruit producers & $32.4 \%(n=12)$ & $25.3 \%(n=21)$ \\
Vegetable producers $^{\text {Number of employees }}{ }^{\mathrm{a}}$ & $67.6 \%(n=25)$ & $74.7 \%(n=62)$ \\
Annual gross revenue (in Euros) $^{\mathrm{a}}:$ & 26 & 5 \\
$\quad<100,000$ & $0.0 \%$ & $8.4 \%$ \\
$100,000-250,000$ & $2.7 \%$ & $19.3 \%$ \\
$250,000-500,000$ & $15.05 \%$ & $28.9 \%$ \\
$500,000-750,000$ & $24.3 \%$ & $19.3 \%$ \\
$750,000-1,000,000$ & $10.8 \%$ & $4.8 \%$ \\
$>1,000,000$ & $48.6 \%$ & $19.3 \%$ \\
Risk attitude $^{\mathrm{b}}$ & 5.0 & 4.2
\end{tabular}

${ }^{\mathrm{a}}$ The number of employees and average annual gross revenue are for 2002.

${ }^{\mathrm{b}}$ Risk attitude is measured as the sum score of the risk-attitude scale, where 1 is highly risk averse and 7 is least risk averse. The risk attitudes between the two segments are significantly different $(p<0.05)$. 
control for both VTN and TG. The lack of transparency in corporate control and product-related management may have made members in segment 2 realize that their own product-portfolio interests are not well addressed by VTN/TG's governance structure. The findings support the assumptions employed in past analytical works (e.g. Banerjee et al., 2001; Reynolds, 1997; Vitaliano, 1983; Zusman, 1992) used to determine that subgroups of members with differing asset ownership (e.g. landholdings, labor input, or amount of product marketed) can lead to conflicting preferences for intra-organizational co-op structure even if all subgroups pursue the same strategic goals. The findings are also in line with the limited empirical evidence (Banerjee et al., 2001; Gripsurd et al., 2001; Iliopoulos \& Cook, 1999) that variance in size of members' operations is an important determinant of co-op structure.

In contrast, differences in the statistical importance of the financial structure on producer membership in the segments offer another instructive interpretation of the relationship among the attributes. The insignificant coefficient in the segment 1 is likely reflective of the small number of producers in the group and the high degree of collinearity that exist between their preferences for members' benefits and financial structure. The positive and significant coefficient in segment 2 , indicating small-sized producers prefer individualized equity, may also be informative by suggesting that even smaller-sized members can see benefits of developing individualized equity opportunities in a highly market-oriented environment like VTN/TG. In a more general context, these findings raise the likelihood that the member preferences structure is not only multidimensional as postulated but also interactive, and they underscore the importance of research design for understanding economic behavior. ${ }^{7}$

Finally, differences in risk-attitude coefficients between the segments seem to partially support the notion that heterogeneity in member preferences for VTN/TG's intra-organizational control is affected by risk preferences. Focusing on risk attitude, we find that risk-attitude has a positive statistical significant effect on the probability of membership in segment 1 . In conjunction with the results from Tables 3 and 4, it appears that larger-sized producers are more willing to risk relinquishing direct producer control of the co-op's operations and direction in hope of adding value through professional management. In contrast, smaller-sized members in segment 2 who are more risk averse prefer critical corporate and product-related decisions control by their representatives.

\section{CONCLUSIONS}

The heterogeneity in the preferences of co-op members has been recognized as an important research topic in the agribusiness economics and marketing literature. In this article, we provide a first effort to directly identify and measure the structure of member preferences for a mix of intra-organization and strategic attributes and to measure factors that affect their heterogeneous nature.

\footnotetext{
${ }^{7}$ The importance of these relationships can be further developed by recognizing the interdependencies among the unique co-op attributes and, allowing different attributes to interact in the research design. Accounting for this possibility by adding profiles can enrich a research design, but at the risk of making it more difficult for respondents to effectively complete the conjoint task (Hair et al., 1998).
} 
We find that members have well-defined preferences for the selected attributes but value the attributes differently. Most members demonstrate similar preferences for strategic attributes but differ with respect to the intra-organizational attributes of control and management. In general, members with large sales who employ a considerable number of workers and exhibit less risk-averse preferences preferred more involvement of professional managers in corporate and product-related decisions. Members with smaller sales and fewer employees and who were more risk averse were more willing to delegate corporate and product marketing control to their representatives who presumably promote their interests more effectively. The similarity in preferences of strategic attributes suggests that members are willing to take similar collective action to capture market advantages. We also find some evidence that strategic and intra-organizational attributes may interact, such that even smaller-sized producers see benefits in non-traditional financial structures. However, the differences in intra-organizational preferences highlight the difficulties that co-ops face in allocating resources efficiently and balancing their commitments to their members.

On balance, the results confirm and extend previous analytical and empirical work on the presence and likely influence of heterogeneous members' preferences (e.g. Banerjee et al., 2001; Reynolds, 1997; Staatz, 1983; Zusman, 1992). The identified differences in preferences for the control mechanisms support the assumptions used to investigate and address co-op organizational inefficiencies in the presence of diverse characteristics. The "large versus small" cost efficiency argument is indeed an important dimension of member preferences for co-op structure and behavior, but our findings also support the recent work identifying the importance of risk attitudes (e.g. Pennings \& Garcia, 2004; Pennings \& Leuthold, 2000; Smidts, 1990) and are consistent with the presence and importance of managing risk in co-op literature (e.g. Buccola \& Subaei, 1985; Sexton, 1986; Schrader, 1989; Zusman, 1992). Our findings also indicate that the structure of member preferences may be both multidimensional and interactive and reinforce the notion that understanding economic behavior within co-ops is challenging and requires careful investigation of the decision context (Cotterill, 2001; Zusman, 1982).

Overall, our analysis identifies a high degree of heterogeneity, which may be problematic for co-op governance and management initiatives. Because the efficiency of resources allocation is threatened as members' heterogeneity increases (Staatz, 1983), the continuous improvement of governance mechanisms that serve various member-segments interests is of value (Reynolds, 1997). Internalization of members' heterogeneous demands and incentives enhances co-ops' ability to avoid outcomes associated with declining member commitment and financial pressures (Fulton \& Giannakas, 2001). At a more practical level, reconciling heterogeneous preferences on a daily basis is a challenge. Nevertheless, identifying the attributes, levels, and factors that influence the preference structure in different member-segments may permit decision makers to extract the essential aspects of a situation. With an understanding of core problems, policies and well-defined ownership structures to meet the fundamental needs of the members may be more readily developed.

Knowledge of the existence of member-segments and an understanding of their preferences may also be useful to co-op policy makers to better evaluate efforts by member subgroups who may strive to influence governance policies. Acquiring such crucial information, conflicting situations that undermine co-op's success in the market may be prevented and continuous development and improvement of services 
that better balance member demands may be achieved. Balancing members demand and avoiding conflicting situations may require the creation and maintenance of formal and informal institutions, such as common norms, formal decentralized decision-making procedures, and performance evaluation by outside experts (Hansmann, 1996, p. 98). Fulton and Gibbings (2000) also propose that the creation of an "umbrella co-op"- a holding organization within which a number of different activities could be carried out - may satisfy the need for a high degree of integration between members' heterogeneous interests and co-op structure. Our results may highlight this need. The diversity in member preferences regarding corporate control and product management may signal the emergence for a multistring governance structure that embodies a wide range of ownership agreements and integrates the revealed preference structure of each participating member-segment.

Several caveats and challenges should be mentioned. First, co-ops have recently experienced an inherently dynamic restructuring process, yet our analysis provides a cross-sectional assessment of members' preference structure for co-op attributes at a specific time. A deeper understanding of the dynamic impact of members' preferences on the structure of co-ops and how this relationship is affected by different economic conditions and changing members' characteristics awaits further empirical analysis. Second, we conceptualized and measured a mix of intra-organizational and strategic attributes in the context of a horticultural marketing co-op. Further research is needed to determine the relative usefulness of these attributes and the factors influencing preference heterogeneity for other types of co-ops. Developing a taxonomy of member preferences by co-op type and the factors that affect these preferences will permit a richer understanding of co-op structure and behavior.

\section{ACKNOWLEDGMENTS}

We are very grateful for the generous participation of the VTN/TG's members in focus-groups sessions (30), pilot test study (8), and final field study (120). Financial support provided by the National Cooperative Council for Horticulture and Agriculture (NCR) in The Netherlands, the AST Chair in Commodity Futures Markets at Wageningen University, The Netherlands Institute of Cooperative Entrepreneurship (NICE), at Nyenrode University, The Netherlands Business School, and the Office for Futures \& Options Research (OFOR) and Marketing \& Decision Sciences Group at the University of Illinois at Urbana-Champaign, IL, USA. We would like to thank J.A. Bijkerk for building a user-friendly interface for the computer-assisted personal interviews. We benefited from comments of participants at several research meetings and conferences (American Agricultural Economics Associations, Marketing Science, Research on Cooperatives, European Science Foundation: Vertical Markets and Cooperative Hierarchies). The authors express special thanks to C. Iliopoulos and M.T.G. Meulenberg who provided helpful comments on the research project and preliminary versions of this paper.

\section{APPENDIX A}

Members were asked to indicate their agreement with each item of risk attitude construct on a 7-point Likert scale ranging from 1 (strongly disagree) to 7 (strongly agree): 
Risk Attitude:

1. I am willing to take higher financial risk to realize higher profit.

2. I am willing to take large financial risks.

3. I am willing to take large financial risks when selling my products to realize higher than average sales.

4. I like to "play it safe" in general.Prior to calculation, the range of responses to number 4 was inverted so that the most pronounced risk-averse response assumed a value of 1 (strongly disagree).

\section{REFERENCES}

Aitkin, M., \& Rubin, D.B. (1985). Estimation and hypotheses testing in finite mixture models. Journal of the Royal Statistical Society, Series B, 47, 67-75.

Banerjee, A.D., Mookherjee, D., Munshi, K., \& Ray, D. (2001). Inequality, control rights, and rent seeking: Sugar cooperatives in Maharashtra. Journal of Political Economy, 109, $138-190$.

Barton, D. (1989). What is a cooperative? In: D. Cobia (Ed.), Cooperatives in agriculture (pp. 1-20). Englewood Cliffs, NJ: Prentice Hall.

Bergman, M.A. (1997). Antitrust, marketing cooperatives and market power. European Journal of Law and Economics, 4, 73-92.

Bijman, W.J.J. (2002). Essays on agricultural co-operatives: Governance structure in fruit and vegetable markets. ERIM PhD Series Research in Management 15. The Netherlands: Erasmus University Rotterdam.

Bijman, W.J.J., \& Hendrikse, G.W.J. (2003). Co-operatives in chains: Institutional restructuring in the Dutch fruit and vegetables industry. Journal on Chain and Network Science, 3, 95-107.

Bozdogan, H. (1987). Model selection and akaike's information criterion (AIC): The general theory and its analytical extension. Psychometrika, 52, 345-370.

Buccola, S.T., \& Subaei, A. (1985). Optimal market pools for agricultural cooperatives. American Journal of Agricultural Economics, 67, 70-80

Bucklin, L.P., \& Sengupta, S. (1993). Organizing successful co-marketing alliances. Journal of Marketing, 57, 32-46.

Chaddad, F.R., \& Cook, M.L. (2004). Understanding new cooperative models: An ownershipcontrol rights typology. Review of Agricultural Economics, 26, 348-360.

Cook, M.L. (1995). The future of U.S. agricultural cooperatives: A neo-institutional approach. American Journal of Agricultural Economics, 77, 1153-1159.

Cook, M.L., Chaddad, F.R., \& Iliopoulos, C. (2004). Advances in cooperative theory since 1990: A review of agricultural economics literature. In: G.W.J. Hendrikse (Ed.), Restructuring agricultural cooperatives (pp. 65-88). The Netherlands: Rotterdam School of Management Publications, Erasmus University Rotterdam.

Cook, M.L., \& Iliopoulos, C. (2000). Ill-defined property rights in collective action: The case of US agricultural cooperatives. In: C. Ménard (Ed.), Institutions, contracts and organizations: Perspectives from new institutional economics (pp. 335-348). Cheltenham: Edward Elgar.

Cotterill, R.W. (2001). Cooperative and membership commitment: Discussion. American Journal of Agricultural Economics, 83, 1280-1281.

DeSarbo, W.S., Wedel, M., Vriens, M., \& Ramaskamy, V. (1992). Latent class metric conjoint analysis. Marketing Letters, 3, 273-282.

Dillon, W.R., Frederick, D.G., \& Tangpanichdee, V. (1985). Decision issues in building perceptual product spaces with multi-attribute rating data. Journal of Consumer Research, $12,47-63$.

Fulton, M.E., \& Giannakas, K. (2001). Organizational commitment in a mixed oligopoly: Agricultural co-operatives and investor-owned firms. American Journal of Agricultural Economics, 83, 1258-1265. 
Fulton, M.E., \& Gibbings, J. (2000). Response and adaptation: Canadian agricultural cooperatives in the 21st century. Saskatoon: Centre for the Study of Co-operatives.

Goldsmith, P.D., \& Gow, H.R. (2005). Strategic positioning under agricultural structural change: A critique of long jump co-operative venture. International Food and Agribusiness Management Review, 8, 1-21.

Green, P.H., \& Rao, V.R. (1971). Conjoint measurement for quantifying judgmental data. Journal of Marketing Research, 8, 355-363.

Green, P.H., \& Srinivasan, V. (1990). Conjoint analysis in marketing: New developments with implications for research and practice. Journal of Marketing, 54, 3-19.

Gripsurd, G., Lenvik, G.H., \& Olsen, N.V. (2001). Influence activities in agricultural cooperatives: The impact of heterogeneity. In S.O. Borgen (Ed.), The food sector in transition-Nordic research (pp. 13-24). NLF Report 01-2. Oslo: Norwegian Agricultural Economics Research Institute.

Hair, J.F., Anderson, R.E., Tathem, R.L., \& Black, W.C. (1998). Multivariate data analysis. Englewood Cliffs, NJ: Prentice-Hall.

Hansmann, H. (1996). The ownership of enterprise. Cambridge, MA: Harvard University Press.

Harris, R.J. (1975). A primer of multivariate statistics. New York: Academic Press.

Hauser, J., \& Rao, V. (2005). Conjoint analysis, related modeling, and applications. In: Y. Wind \& P. E. Green (Eds.), Market research and modeling: Progress and prospects (pp. 141-168). New York: Springer Academic Publications.

Heckman, J.J. (2001). Micro data, heterogeneity, and the evaluation of public policy: Nobel Lecture. Journal of Political Economy, 109, 673-748.

Hendrikse, G.W.J., \& Bijman, W.J.J. (2002). On the emergence of new growers' associations: Self-selection versus market power. European Review of Agricultural Economics, 29, 255-269.

Hendrikse, G.W.J., \& Veerman, C.P. (1997). Marketing cooperatives as a system of attributes. In: J. Nilsson \& G. Van Dijk (Eds.), Strategies and structures in the agro-food industries (pp. 111-130). Assen, The Netherlands: van Gorcum.

Holmstrom, B. (1999). Future of cooperatives: A corporate perspective. Finish Journal of Business Economics, 48, 404-417.

Iliopoulos, C. (1998). A study of the property rights constraints in U.S. agricultural cooperatives: Theory and evidence. Unpublished doctoral dissertation, University of Missouri-Columbia, US.

Iliopoulos, C., \& Cook, M.L. (1999). The efficiency of internal resource allocation decisions in customer-owned firms. Paper presented at the 3rd Annual Conference of International Society for New Institutional Economics, Washington DC.

Kalogeras, N., Pennings, J.M.E., Van Dijk, G., \& van der Lans, I.A. (2007). The structure of marketing cooperative: A members' perspective.' In: K. Karantininis \& J. Nilsson (Eds.), Vertical markets and cooperative hierarchies (pp. 73-92). Dordrecht, The Netherlands: Springer Academic Publications.

Knoeber, C.R., \& Baumer, D.L. (1983). Understanding retained patronage refunds in agricultural cooperatives. American Journal of Agricultural Economics, 56, 30-37.

Kyriakopoulos, K. (2000). The market orientation of cooperative organizations: Learning strategies and structures for integrating firm and members. Unpublished doctoral dissertation, Nyenrode University, Assen, The Netherlands, van Gorsum.

March, J.G., \& Shapira, Z. (1987). Managerial perspectives on risk and risk taking. Management Science, 33, 1404-1418.

Meulenberg, M.T.G. (1979). Farmer cooperatives in the food economy of western Europe: An analysis from the marketing point of view. European Review of Agricultural Economics, 5, 255-275

Meulenberg, M.T.G. (2000). Voluntary marketing institutions in food marketing systems. In: A. Tilburg, H.A.J. van Moll, \& A. Kuyvenhoven (Eds.), Agricultural markets beyond liberalization (pp. 213-233). Dordrecht, The Netherlands: Kluwer Academic Publishers.

Olson, M. (1965). The logic of collective action. Cambridge, MA: Harvard Business Press.

Oustapassidis, K., Vlachvei, A., \& Karantininis, K. (1998). Growth of investor-owned and cooperative firms in Greek dairy industry. Annals of Public and Cooperative Economics, 16, 315-325. 
Pennings, J.M.E., \& Smidts, A. (2000). Assessing the construct validity of risk attitude. Management Science, 46, 1337-1348.

Pennings, J.M.E., \& Garcia, P. (2004). Hedging behavior in small- and medium-sized enterprises: The role of unobserved heterogeneity. Journal of Banking \& Finance, 28, 951-978.

Pennings, J.M.E., \& Leuthold, R.M. (2000). The role of farmers' behavioral attitudes and heterogeneity in future contracts usage. American Journal of Agricultural Economics, 82, 908-919.

Peterson, C.H., \& Anderson, B.L. (1996). Cooperative strategy: Theory and practice. Agribusiness: An International Journal, 12, 371-383.

Porter, M.E. (1985). Competitive advantage: Creating and sustaining superior performance. New York: Free Press.

Reynolds, B.J. (1997). Decision making in cooperatives with diverse member interests. RBS Service Rep. 155, April. Washington, DC: US Department of Agriculture.

Rohner, R.P. (1977). Advantages of the comparative method of anthropology. Behavior Science Research, 12, 117-144.

Schrader, L.F. (1989). Economic justification. In: D.W. Cobia (Ed.), Cooperatives in agriculture (pp. 121-136), Englewood Cliffs, NJ: Prentice Hall.

Sexton, R.J. (1986). Cooperatives and the forces shaping agricultural marketing. American Journal of Agricultural Economics, 68, 1167-1172.

Smidts, A. (1990). Decision making under risk: A study of models and measurement behavior with special reference to the farmer's marketing behavior. Wageningen Economic Studies No. 18. Wageningen, The Netherlands: Academic Publishers.

Staatz, J.M. (1983). The cooperative as a coalition: A game theoretic approach. American Journal of Agricultural Economics, 65, 1084-1089.

Staatz, J.M. (1987). The structural characteristics of farmer cooperatives and their behavioral consequences. In J.S. Royer (Ed.), Cooperative theory: New approaches, ACS Service Rep. 18, July. Washington, DC: US Department of Agriculture.

Sterns, J.A., Schweikhardt, D.B., \& Peterson, H.C. (1998). Using case studies as an approach for conducting agribusiness research. International Food and Agribusiness Management Review, 1, 311-327.

Titterington, D.M. (1990). Some recent research in the analysis of mixture distributions. Statistics, 4, 619-641.

U.S.D.A. (1995). What is a cooperative? Rural Business and Cooperative Development Service, Cooperative Information Report 50, March. Washington DC: Author.

Van Bekkum, O.-F. (2001). Cooperative models and farm policy reform: Exploring patterns in structure-strategy matches of dairy cooperatives in protected vs. liberated markets. published? Unpublished doctoral dissertation, Nyenrode University, Assen, The Netherlands, van Gorsum.

Van Bekkum, O.-F., \& Van Dijk, G. (Eds.), (1997). Agricultural cooperatives in the European Union-Trends and issues on the eve of the 21st Century. Assen, The Netherlands: van Gorsum.

Van Dijk, G., \& Mackel, C. (1991). Dutch agriculture seeking for market leader strategies. European Review of Agricultural Economics, 18, 345-364.

Vitaliano, P. (1983). Cooperative enterprise: Alternative conceptual basis for analyzing a complex institution. American Journal of Agricultural Economics, 65, 1078-1082.

Wedel, M., \& DeSarbo, W.S. (1995). A mixture likelihood approach for generalized linear models. Journal of Classification, 12, 21-55.

Wedel, M., \& Kamakura, W.A. (1998). Market segmentation: Conceptual and methodological foundations (2nd ed.) - International series in quantitative marketing. Boston: Kluwer Academic Publishers.

Zusman, P. (1982). Group choice in an agricultural marketing cooperative. Canadian Journal of Economics, 15, 220-234.

Zusman, P. (1992). Constitutional selection of collective-choice rules in a cooperative enterprise. Journal of Economic Behavior and Organization, 17, 353-362. 
Nikos Kalogeras studied economics (BSc), economics \& management sciences (MA), marketing \& consumer behavior (MSc), and financial engineering and management (M.Eng). He also attended a series of PhD courses and seminars at the University of Illinois at Urbana-Champaign. Nowadays, he is a post-graduate fellow and lecturer in the Department of Finance and the Department of Marketing at Maastricht University (the Netherlands). His current research interests mainly focus on individual market actors' (producers, consumers, investors) behavior regarding strategic marketing and financial decisions.

Joost M.E. Pennings is a professor in the Department of Marketing and the Department of Finance at Maastricht University in the Netherlands, a professor in the Department of Agricultural and Consumer Economics at the University of Illinois at Urbana-Champaign, and the AST Professor of Marketing at Wageningen University in the Netherlands. His current research deals with understanding revealed economic behavior by studying the decision-making behavior of real decision-makers (market participants, consumers, managers, etc).

I. A. van der Lans holds a PhD in data theory and analysis, an MSc in psychometrics and research methodology, and a BSc in psychology from Leiden University in the Netherlands. He is an assistant professor in the Department of Marketing and Consumer Behavior at Wageningen University in the Netherlands. His current research interests are consumer behavior, agricultural marketing research, and quantitative research methodology and data analysis.

Philip Garcia holds a PhD in agricultural economics and an MSc in agricultural economics from Cornell University as well as a BSc in economics from Occidental College. He is the professor Thomas A. Hieronymus Distinguished Chair in Futures Markets, and Director of the Office of Futures and Options Research (OFOR), Department of Agricultural and Consumer Economics, University of Illinois at Urbana-Champaign. His current research interests are agricultural price analysis, futures and options markets, risk management, and behavior under risk.

Gert van Dijk is a professor in the Department of Marketing and Consumer Behavior at Wageningen University in the Netherlands and professor at and chairman of The Netherlands Institute of Cooperative Entrepreneurship at Nyenrode Business School in the Netherlands. He is also the president of the General Committee for Agricultural Cooperation in the European Union (COGECA) and the director general of The Dutch National Council of Cooperatives. His current research interests are cooperative entrepreneurship, agribusiness marketing-management, and food marketing. 